\title{
INTEGRAL MEAN ESTIMATES FOR POLYNOMIALIS WITH RESTRICTED ZEROS
}

\author{
ABdul AZIZ AND Wali MoHAmmad SHAH
}

Abstract. Let $P(z)$ be a polynomial of degree $n$ which does not vanish in the disk $|z|<K$. For $K=1$, it is known that for $0<q<\infty$,

$$
\left\{\frac{1}{2 \pi} \int_{0}^{2 \pi}\left|P\left(R e^{i \theta}\right)\right|^{q} d \theta\right\}^{1 / q} \leqslant B_{q}\left\{\frac{1}{2 \pi} \int_{0}^{2 \pi}\left|P\left(e^{i \theta}\right)\right|^{q} d \theta\right\}^{1 / q}
$$

where

$$
B_{q}=\left\{\frac{1}{2 \pi} \int_{0}^{2 \pi}\left|1+R^{n} e^{i n \alpha}\right|^{q} d \alpha\right\}^{1 / q} /\left\{\frac{1}{2 \pi} \int_{0}^{2 \pi}\left|1+e^{i n \alpha}\right|^{q} d \alpha\right\}^{1 / q} .
$$

In this paper we present a generalization of this result by considering the case $K \geqslant 1$. We shall also prove a similar result for polynomialis having all their zeros in $|z| \leqslant K$, where $K \geqslant 1$.

\section{Mathematics subject classification (2000): 26D05, 30D15, 41A17.}

Key words and phrases: Integral mean estimates, admissible operator, complex domain inequalities.

\section{REFERENCES}

[1] A. C. Ankeny And T. J. Rivlin, On a theorem of S. Bernstein, Pacific J. Math 5 (1955), 849-852.

[2] V. V. ARESTOV, On inequalities for trigonometric polynomials and their derivatives, Izv. Akad. Nauk SSSR Ser. Mat. 45 (1981), 3-22.

[3] A. AzIZ, Integral mean estimates for polynomials with restricted zeros, J. Approx. Theory 55 (1988), 232-239.

[4] A. AzIZ And Q. G. Mohammad, Growth of polynomials with zeros outside a circle, Proc. Amer. Math. Soc. 81 (1981), 549-553.

[5] R. P. BOAS, JR. AND Q. I. RAHMAN, $L^{p}$ inequalities for polynomials and entire functions, Arch. Rational Mech. Anal. 11 (1962), 34-39.

[6] G. H. Hardy, The mean value of the modulus of na analytic function, Proc. London Math. Soc. 14 (1915), 269-277.

[7] M. A. MaLIK, An integral mean estimate for polynomials, Proc. Amer. Math. Soc. 91 (1984), $281-284$.

[8] G. Polya AND G. SzEGÖ, Aufgaben and Lehrsätze aus der Analysis, Springer-Verlag, Berlin, 1925.

[9] Q. I. RAHMAN AND G. SchmeISSER, Les inégalités de Markoff et de Bernstein, Presses Univ. Montréal, Montréal, Quebec, 1983.

[10] Q. I. RAHMAN AND G. SchmeIsser, $L^{p}$ inequalities for polynomials, J. Approx. Theory 53 (1998), 26-32.

[11] M. RIESZ, Über einen satz des Herrn Serge Bernstein, Acta Math. 40 (1916), 337-347. 